\title{
Case Report \\ A case of acute psittacosis with severe abdominal pain
}

\author{
Takahiro Homma, ${ }^{1}$ Toshiyuki Yamaguchi, ${ }^{2}$ Nobuo Komatsu, ${ }^{2}$ \\ Shinichi Hashimoto, ${ }^{2}$ Yoshinori Doki, ${ }^{1}$ Kazutaka Senda, ${ }^{1}$ \\ Naoki Yoshimura ${ }^{1}$ and Naoyuki Miyashita ${ }^{3}$ \\ ${ }^{1}$ First Department of Surgery, University of Toyama, Toyama, Japan \\ ${ }^{2}$ Division of Surgery, Komoro Kohsei General Hospital, Komoro, Nagano, Japan \\ ${ }^{3}$ Division of Respiratory Disease, Kawasaki Medical School, Kurashiki, Okayama, Japan
}

Correspondence

Takahiro Homma

hommat@med.u-toyama.ac.jp

\begin{abstract}
We report the case of a psittacosis patient with severe abdominal pain who subsequently developed acute respiratory failure. The main symptoms of psittacosis are considered to be upper respiratory inflammation and influenza-like symptoms. However, it should be emphasized that digestive symptoms can be prominent in psittacosis patients. Early diagnosis of this condition is difficult and there is a need for an effective method for rapid diagnosis.
\end{abstract}

Received 28 May 2010
Accepted 24 December 2010

\section{Introduction}

Psittacosis is a zoonotic infection caused by Chlamydophila psittaci that occurs through inhalation of the causative organism from excretions from an infected bird. Clinically, upper respiratory inflammation and influenza-like symptoms are dominant. Herein, we report the case of a patient with psittacosis who visited our department with severe abdominal pain and subsequently developed acute respiratory failure.

\section{Case report}

The patient was a 50 -year-old male with a previous history of gastric ulcers, who experienced right epigastric pain 2 days before visiting our hospital. He was non-smoker, and did not have chronic obstructive pulmonary disease, cardiac disease or collagen disease. He came to the outpatient department for pain progression and was admitted to the Emergency Surgery Department with severe pain in the right upper abdomen. Muscular defence was noted, with no rebound tenderness. His body temperature was $37.6{ }^{\circ} \mathrm{C}$, and there were no respiratory symptoms or audible rales. Abnormal haematological findings were an elevated white blood cell count of $17200 \mathrm{~mm}^{-3}$ and C-reactive protein of $9.6 \mathrm{mg} \mathrm{dl}^{-1}$. Other than these, no abnormalities were found in urinalysis, simple thoracoabdominal X-ray (Fig. 1a), abdominal contrast computed tomography and upper gastrointestinal endoscopy examinations. A bloody nose at the time of admission was also noted.

We administered the antibiotic cefmetazole; however, the symptoms did not improve. On the third hospital day, the pain had migrated from the right upper abdomen to the

Abbreviation: MIF, microimmunofluorescence. right axilla and thoracodorsal area. The patient developed respiratory failure after that pain transition, for which artificial respiration was required in the intensive care unit. He was diagnosed with double pneumonia and pleurisy, and acute respiratory distress syndrome, as the $\mathrm{PaO}_{2} / \mathrm{FiO}_{2}$ ratio was 142 , with right-dominant infiltrative shadows in the bilateral lung, and accumulations of pleural effusion and pulmonary atelectasis in the right middle and lower lobes in chest X-ray and computed tomography findings (Fig. 1b).

It was difficult to determine the causative factor on the basis of occupational history, living environment and clinical records. The patient was negative for serum HIV antibody, influenza virus rapid antigen, serum mycoplasmal antibody, urine Legionella antigen, urine pneumococcal antigen and serum $\beta$-glucan, though positive in a procalcitonin qualitative test $\left(>0.5 \mathrm{ng} \mathrm{ml}^{-1}\right)$. Furthermore, he was negative in an acid-fast bacillus cultivation test of pleural effusion and coughed-up sputum, as well as for QuantiFERON-TB-2F and pleural effusion adenosine deaminase. Although we gave antibiotics and imipenem/cilastatin sodium, to which sivelestat sodium hydrate was added, the symptoms did not improve. At 7 days after intensive care unit admission, the Chlamydia pneumoniae IgM elevated to 1.21 and $\operatorname{IgG}$ to 1.69 in the ELISA (Hitazyme C. pneumoniae; Hitachi Chemical) results. Accordingly, the antibiotics were replaced with minocycline, after which the respiratory condition, examination results and pain improved. He was discharged from the hospital 5 days after the antibiotic change and was negative for procalcitonin at the time of writing.

Following discharge, serum samples were examined using microimmunofluorescence (MIF) assays at Kawasaki Medical School. At admission, the IgM and IgG titres for C. psittaci were each lower than $1: 16$, while on the 20th 
(a)

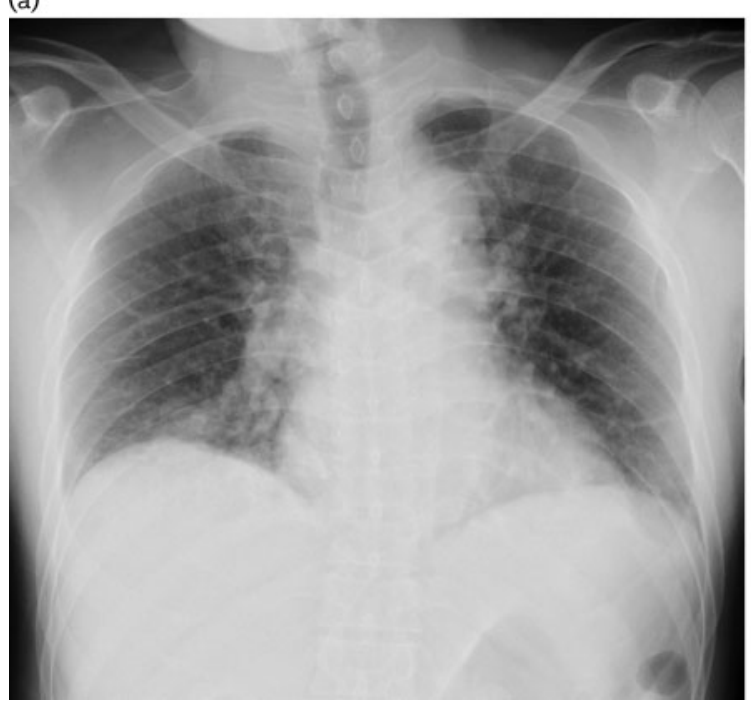

(b)

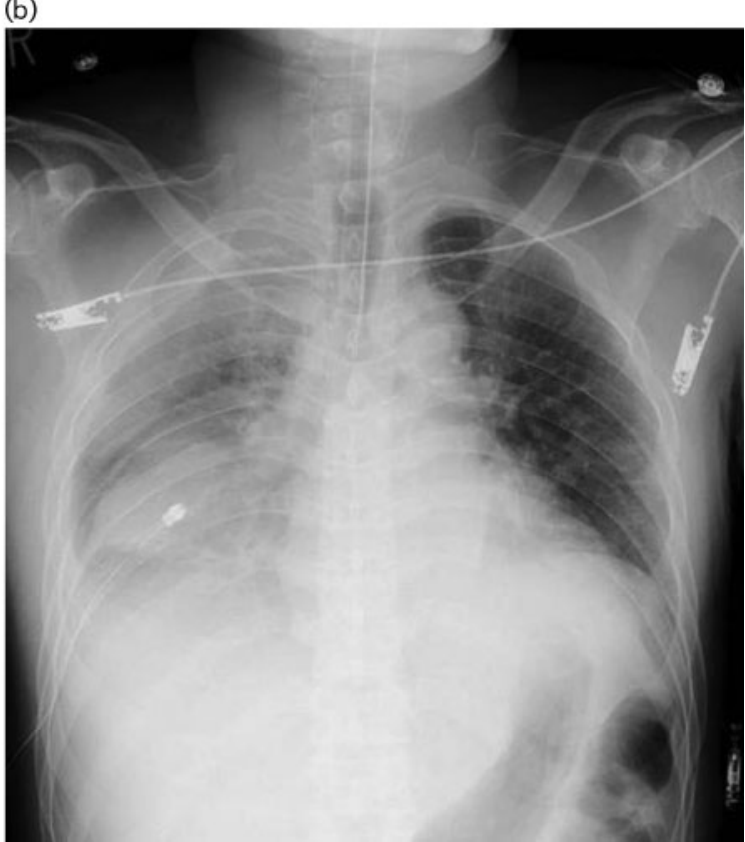

Fig. 1. (a) Simple chest $X$-ray taken on admission revealing no significant abnormalities. (b) Simple chest X-ray image after respiratory failure revealing infiltrative shadows, reduced permeability and pleural effusion in the right lung field.

hospital day, that of $\operatorname{IgG}$ was $1: 16$ and the $\operatorname{IgM}$ titre was elevated to $1: 32$. On the basis of these findings, we gave a final diagnosis of acute psittacosis. However, no significant findings were obtained for $C$. pneumoniae, because all the $\operatorname{IgM}$ and IgG titres were lower than $1: 16$. There was no obvious contact with birds in the occupational history or living environment of the patient. Thus, the source of infection was not identifiable.

\section{Discussion}

According to the legal requirements in Japan, notification of psittacosis infection must be made to health officials. About 30 cases each year are reported (Infectious Disease Surveillance Center, Japan National Institute of Infectious Diseases). Thus, doctors in fields other than respiratory tract medicine seldom have the opportunity to encounter affected patients.

Causes of abdominal pain of extraperitoneal origin include pneumonia and pleuralgia (Fauci et al., 2005). Crosse (1990) reported that abdominal pain was observed in $9 \%$ of patients with psittacosis, while vomiting was seen in $42 \%$, diarrhoea in $25 \%$, constipation in $22 \%$ and nausea in $14.5 \%$. Byrom et al. (1979) also reported splenohepatomegaly and pancreatitis in psittacosis patients. The major complaint of psittacosis is considered to be respiratory symptoms due to pneumonia, whereas abdominal symptoms are not commonly known. In fact, emergency laparotomy procedures have been performed in such cases of unknown cause (Bourne et al., 2003). It has also been reported that nasal haemorrhaging not immediately noted by the patient occurred in $25 \%$ of psittacosis cases as an early symptom (Fauci et al., 2005). It is difficult to make a diagnosis of psittacosis in cases such as the present without respiratory symptoms or a possible pathogen on the basis of the clinical record.

We suspected a bacterial aetiology on the basis of positive serum procalcitonin findings and atypical pleurisy associated with pleural effusion shown by imaging findings in this case. Though C. pneumoniae does not induce pleurisy, we tested for this using an ELISA (Hitazyme $C$. pneumoniae) (Kishimoto et al., 2009). Though 'falsepositives' related to rheumatoid factor and other factors have been reported for adults with this kit (Miyashita et al., 2010), the passage after we prescribed minocycline strongly suggested chlamydial infection.

Minocycline was not administered until ELISA results were obtained and 1 week passed before identification of the causative organism. Although it has been reported that the fatality rate associated with psittacosis is under $1 \%$, it would be desirable to establish a testing method that enables more rapid diagnosis, as fatalities have been reported in recent years (Petrovay \& Balla, 2008).

The MIF test is the current gold standard for serological testing for chlamydial infections worldwide. The IgM diagnostic criteria for single serum samples have been established for Wang's MIF test (Wang \& Grayston, 1970). The serum had an IgM titre rising from $<1: 16$ at admission to $1: 32$ on the 20th hospital day for C. psittaci, indicating an acute infection. MIF IgM and IgG antibodies should respond 20 days after onset in C. pneumoniae 
infections (Wang, 2000), but there were no significant results for this organism. Because the respiratory samples were not stored, it was impossible to test for chlamydial species by a molecular method (PCR).

Procalcitonin levels are known to be elevated in serious bacterial infections (Assicot et al., 1993), as reflected in the fatality rate (Okimoto et al., 2009). There have been few reports on the relationship of procalcitonin level with disease aetiology and none in regard to psittacosis (Delèvaux et al., 2003). It has also been reported that LPS is involved in stimulation of procalcitonin production (Linscheid et al., 2003). In psittacosis patients, LPS is mainly present in the enveloping membrane of the pathogenic elementary body (EB), which is disseminated in a haematogenous manner (Azuma \& Oguma, 1995). In the present case, procalcitonin levels fluctuated before and after treatment, which may indicate that serum procalcitonin levels are related to blood EB levels and might be useful for evaluating the severity, septic symptoms and therapeutic effects in Chlamydia infection, including psittacosis.

\section{Conclusion}

Psittacosis varies clinically, which makes early diagnosis difficult, thus establishment of a rapid diagnostic method is desirable. As seen in the present patient, it is important to keep in mind that digestive symptoms can develop in psittacosis patients.

\section{Acknowledgements}

The authors thank Dr Yuki Masuda, and Dr Masahiro Hayashi (Division of Surgery, Komoro Kohsei General Hospital) for support with treatment. This research was supported by the Division of Respiratory Disease, Department of Internal Medicine, Kawasaki Medical School.

\section{References}

Assicot, M., Gendrel, D., Carsin, H., Raymond, J., Guilbaud, J. \& Bohuon, C. (1993). High serum procalcitonin concentrations in patients with sepsis and infection. Lancet 341, 515-518.
Azuma, M. \& Oguma, K. (1995). Simple Microbiology, 2nd edn. Tokyo: Nankodo.

Bourne, D., Beck, N. \& Summerton, C. B. (2003). Chlamydia psittaci pneumonia presenting as acute generalised peritonism. Emerg Med $J$ 20, 386-387.

Byrom, N. P., Walls, J. \& Mair, H. J. (1979). Fulminant psittacosis. Lancet 1, 353-356.

Crosse, B. A. (1990). Psittacosis: a clinical review. J Infect 21, 251259.

Delèvaux, I., André, M., Colombier, M., Albuisson, E., Meylheuc, F., Bègue, R. J., Piette, J. C. \& Aumaître, O. (2003). Can procalcitonin measurement help in differentiating between bacterial infection and other kinds of inflammatory processes? Ann Rheum Dis 62, 337340.

Fauci, A., Braun, E., Kasper, D., Hauser, S., Longo, D., Jameson, J. \& Loscalzo, J. (2005). Harrison's Principles of Internal Medicine, 16th edn. Columbus, OH: McGraw-Hill Professional.

Kishimoto, T., Ando, S., Numazaki, K., Ouchi, K., Yamazaki, T. \& Nakahama, C. (2009). Assay of Chlamydia pneumoniae-specific IgM antibodies by ELISA method - reduction of non-specific reaction and resetting of serological criteria by measuring IgM antibodies -. Jpn J Infect Dis 62, 260-264.

Linscheid, P., Seboek, D., Nylen, E. S., Langer, I., Schlatter, M., Becker, K. L., Keller, U. \& Müller, B. (2003). In vitro and in vivo calcitonin I gene expression in parenchymal cells: a novel product of human adipose tissue. Endocrinology 144, 5578-5584.

Miyashita, N., Kawai, Y., Yamaguchi, T., Ouchi, K., Kobashi, Y. \& Oka, M. (2010). Evaluation of false-positive reaction with ELISA for the detection of Chlamydophila pneumoniae-specific IgM antibody in adults. Jpn J Infect Dis 63, 150-151.

Okimoto, N., Hayashi, Y., Ishiga, M., Nanba, F., Kishimoto, M., Yagi, S., Kurihara, T., Asaoka, N. \& Tamada, S. (2009). Procalcitonin and severity of community-acquired pneumonia. J Infect Chemother 15, 426-427.

Petrovay, F. \& Balla, E. (2008). Two fatal cases of psittacosis caused by Chlamydophila psittaci. J Med Microbiol 57, 1296-1298.

Wang, S. P. (2000). The microimmunofluorescence test for Chlamydia pneumoniae infection: technique and interpretation. $J$ Infect Dis 181, S421-S425.

Wang, S. P. \& Grayston, J. T. (1970). Immunologic relationship between genital TRIC, lymphogranuloma venereum, and related organisms in a new microtiter indirect immunofluorescence test. Am J Ophthalmol 70, 367-374. 